\title{
The relationship between education and income inequality (the case of Pakistan)
}

\author{
SeemaRehman ${ }^{1 *}$, Muhammad Zaki Rashidi ${ }^{2}$ \\ ${ }^{1}$ MS student of Management Sciences at SZABIST \\ ${ }^{2}$ Faculty member at SZABIST \\ *Corresponding author E-mail: seemarehman2012@gmail.com
}

\begin{abstract}
The Income Inequality refers to the unequal distribution of family or individual wealth among the inhabitants of a particular economy. It is often determined by the percentage of income to a percentage of population. Like 50\% of Pakistan's income is controlled by the highest $20 \%$ population. It is generally thought of as "unjust," if the major share of a country's income goes to the rich. Many researches have been done to find the level of Income Inequality in Pakistan, but these researches are not comparable because of differences in techniques, selection of welfare determinant, choice of data (individual or family incomes) and difference in indices for inequality measurement. It is also observed that two studies give contradictory results for the same period. This research tries to fill the gap by measuringthe impact of education on unequal distribution of income in Pakistan. The study uses Gini Coefficient method to measure Income Inequality in Pakistan by taking data available at the websites of PSLM (Pakistan Social and Living Standards Measurement Survey), HIES (Household Income and Expenditure Survey) and MDG's (Pakistan Millennium Development Goals).This This paper tries to determine the effects of various components of education on Income Inequality. Progress in education is judged by assessing three indicators: Primary Enrolment Rate, Completion Rate (grades 1-5) and Adult Literacy Rate. In this research, we define Adult Literacy Rate as Tertiary Rate as it includes population of ages 15 years and older. The pooled cross sectionaldata considered in this study is for the periods 2004/05, 2007/08 and 2010/11 The results of regression are as expected, which shows an unambiguously negative association between Primary Enrolment Rate andIncome inequality, however, as concluded by Barro (1996), it is validated that inequality increases with higher education. Therefore, an increase in schooling helps distributes income justifiably.
\end{abstract}

Keywords: Income Inequality; Gini Coefficient; Tertiary.

\section{Introduction}

The distribution of wealth plays an important role in determining the economic development of a country, as it has been broadly accepted that the concentration of income into the hands of a few, results in social tensions. On the other hand, equality in income improves the socioeconomic conditions within the society and its inhabitants.

\subsection{Background}

In Pakistan, there was high growth in the decades of 1960s and 1980 s and it witnessed low growth in 1990s. High growth normally helps in the reduction of poverty, if it is distributed equitably and low economic growth increases poverty and inequality. If the economic growth is high but distribution of income is unequal, it may still contribute in increasing the level of poverty in a country as it happened in Pakistan in the 1960s. On the other hand, if economic growth is low but there exists equality in income among the masses, it reduces the level of poverty to some extent as is the case in Pakistan in 1970s. In Pakistan, the disparities in income also explain the unequal distribution of assets. The lowest $20 \%$ are working in the primary sector of the economy, in which the major portion of the wealth is controlled by few landlords, and the poor surfs receive minimum wages, which is exacerbating the problem. Even though federal government has taken measures to help common citizen by giving plots and announcing projects, but the existing corruption in our system blocks any improvement. Shifting of resources from the primary sector to the tertiary sector has also been observed, moving the poor further above the poverty level. Another reason is the regressive type of tax system in our country, which is benefiting the rich, who enjoy huge incomes. Poor are facing shortages of basic necessities of life, which financial analysts fear, may lead to civil war in the country if the authorities do not take any serious measures to control the increasing gap in the incomes of the poor and the rich.

Income distortions arise because of many reasons, some are,changes in incomes in the labor market, choice of occupation and demographic pattern of the population. Quality of education plays an important role in determining incomes of an individual in the labor market. Students from private institutions are paid more as compared to those from government schools. Gender disparity is also common in Pakistan. It is thought that women could not contribute as much time to their professions as men. Income inequality is greater in rural areas because of the low level of education, lack of infra-structure and larger families.

Many researchers have contributed in the findings of unequal distribution of income in Pakistan by taking last forty years data into consideration. These researches are not comparable because 
of differences in techniques, selection of welfare determinant, choice of data (individual or family incomes) and difference in indices for inequality measurement. It is also observed that two studies give contradictory results for the same period. Considering these limitations, Anwer (2005) used consistent methods to find out Gini Coefficients by using data on grouped incomes. His results suggest that income inequalities in Pakistan have been rising since 1990s and the same pattern continues in the current decade.

\subsection{Problem statement}

The problem of income inequality is influenced by how much, by all the factors, since some of the factors like education, could produce both negative and positive effects. The main objective of any study should be to work for the welfare of the individuals and the society. This question was raised in the mid1960s that despite the increase in economic growth, the poverty level did not reduce because of the increase in income inequalities. $70 \% \%$ of Pakistan's public reside in villages and is engaged in agricultural sector. Since 1960s, the annual GDP growth rate is over $5 \%$. It is believed that the economic growth in general and growth, particularly in agricultural sector has not improved the living standards of the poor. As some economists are of the view that new advancement favors trained or skilled labors, so the benefit goes to the rich

\subsection{Objectives of the research}

To identify the association between income inequality and education in Pakistan and how it is both negatively and positively related to it, at primary and higher level. This research focuses upon the nature of the relationship between income inequality and some of the factors that are responsible for increasing or decreasing the gap like differences in wages, differences in education, population growth, taxation system and trade liberalization. Expenditure data is considered more reliable estimator in determining inequality in incomes as both richest and poorest are reluctant to tell about their incomes. Rich save most of their income and poor borrow money to meet their daily needs, so in Pakistan; we use both income and expenditure data to derive the inequalities.

\subsection{Factors affecting income inequality}

Income inequality is dependent on many variables, negatively or positively. Human development, trade liberalization, is negatively related to income inequality, when there's high human development, income inequality will be lower. Population growth, differences in wages, regressive taxation, ethnic discrimination, gender discrimination and nepotism are some of the variables, positively related to inequality.

\subsubsection{The labor market}

A major cause of unequal distribution of income is the differences in wages in the labor market. Supply and demand cause these differences, especially in an imperfect market, where the information is not evenly distributed and acquiring education or skills is unequal. In a pure capitalistic market, wages are not controlled by professional or labor unions by limiting the supply but by the market, like the price of any other good. A job in which, there are large number of people willing to work and the job requires few, will reduce the salary for that work as too much supply sets down the earnings. A profession where the supply of competitive labor is low and demand for workers is high will set the salaries high for that profession. Polarization of salaries helps explaining the accumulation of wealth.

\subsubsection{Trade liberalization}

The influence of trade liberalization on income distribution has received great attraction among policy maker officials in under developed countries in last twenty years. Economic broadness promotes competition, which leads to the production of quality products throughout the country. Trade openness widens the market, helps in technological advancement and reallocates labor force in new sectors. The new classical theory of international trade suggests that, openness enhances the return on the factor, which is supplied in abundance and inversely decreases the return on scarce factor. Thus in Pakistan as the unskilled labor is in excessive supply, trade openness will help to increase their incomes, thereby reducing income inequality. Openness also helps in the establishment of new industries that could help improve employment and earnings in numerous areas. And as textiles adjust women workers as well, expansion of textiles industries reduce discrimination between male and female labor.

\subsubsection{Education}

As per our national educational policy, Our education system must provide quality education to our children and youth to enable them to realize their individual potential and contribute to development of society and nation, creating a sense of Pakistani nationhood, the concepts' of tolerance,social justice, democracy, their regional \& local culture and history based on the basic ideology enunciated in the Constitution of the Islamic Republic of Pakistan.

In Pakistan, one important factor creating inequality is the disparities in educational system. Educational opportunities help poor to get larger part of the income from economic growth. First, lack of education directly results in lower incomes and these lower earnings lead to greater illiteracy in future. There is a relationship between unequal distribution of income and education in terms of the return on education. In the present scenario of technological advancement and globalization, the need for skilled labor is continuously rising and the demand for unskilled workers is declining, resulting in wage differences and eventually widening gap between rich and poor. Even if the greater economic goal is not recognized, education is very important for an individual and is considered as a basic human right. Therefore it is responsibility of government to deliver access to everyone without discrimination. We live in a highly sectored society, which is degenerated by class wars. Most of the schools established by government are Urdu medium, meant to provide education to the lower class, who cannot afford to go to the private schools. This results in better jobs for the rich and low paid jobs for the poor. In countries, where there is equitable distribution of education, the level of poverty is low because poor are able to capture larger share of the economic growth.

Developing human capital by enhancing educational skills played a significant role in the economic growth of a country. Education provides opportunities for everyone by improving living standards. Most of the countries of the world have recognized education as a basic human right, through conventions and policies. Education has become very important in today's mercurial world faced with globalization, technological advancement sand establishment of new market economies. States need technical and skilled population, and people need high education and information to survive and compete. Wide income gap reflects under investment in education that results into long run low economic growth. United Nations have mentioned gender, ethnicity and disability as the characteristics of discrimination in providing education. The link between education and Income Inequality is not clear, when analyzing the basic factors responsible for causing the variation in incomes. On the one hand, rising inequalities in wages should increase investment in human capital because it increases the return on education. This rising supply of skilled labor should mitigate the inequality gap.

On the other hand, rising inequality affects the incomes of households, which they can utilize to invest in education, as there is a perfect correlation between education and income distributions. This reveals that barriers like family background or liquidity constraints might be responsible for under investment in education for the lowest population. According to intergenerational mechanism, 
this fraction of population gets trapped in low levels in educational attainment for generations.

Our population comprises of God gifted talented individuals, but due to unsecured environment and lack of employment opportunities, a large number of professionals leave Pakistan in search of better life and career. For solving this problem, governments have provided facilities to improve research activities in higher institutions. HEC offers need based scholarships, especially to students of Balochistan and FATA. Thousands of students study abroad, financed by HEC scholarship programs. Pakistan is an Islamic country, and Islam asserts importance of education for both male and female without discrimination. Pakistan is a developing country faced with challenges like establishing Human-Resource Development (HRD) programs and meeting socioeconomic goals, tabulating authentic data for better evaluation of indicators of education for extrapolating future projects and planning language policy for schools in collaboration with provincial governments. PSLM provides comprehensive and integrated data on education by reporting details about Literacy rate and Net primary enrolment. PSLM survey is a good source to overview areas requiring serious efforts, by producing details regarding key indicators of education.

\subsection{Justification}

1) Policy makers can benefit from this study, by knowing that why their past policies haven't been working in the right direction.

2) Public will take benefit from this research by taking part in the government programs initiated after the results, designed to promote small sector businesses.

3) Government my revise its tax system after such studies and suggestions, which may help to fill the gap.

\subsection{Limitations}

1) As a sample size of 74000 participants was used in the past study by HIES and PIHS, so the sample size used in this research may not give the accurate picture.

2) In this study the main perspective is to help the poor, so the interests of the upper class will not be taken into account.

3) Data comparison with the past data may not give the real picture because of the expected partiality in records.

\subsection{Scope}

The small size of the population like few thousands could be used to estimate about millions of the same population because of the similarity of the circumstances. People living in rural areas and people living within urban areas face the same type of economic conditions.

\subsection{Assumptions}

1) Incomes of the population in this study will stay the same during the research period.

2) All government policies will not change during this research.

3) People will be truthful in telling about their incomes from all sources.

\subsection{Definitions of key terms}

Lorenz Curve: By using Lorenz Curve, we can get complete picture of the income distribution as a whole, in terms of mean. If the data is close to the 45 degree line, people are receiving same level of incomes and if the data is farther away from the 45 degree line, there's a higher level of income inequality.

Gini Coefficient: Income disparities can be calculated in a more accurate manner by using GiniCoefficient. It can take values between 0 to 1 . If the value is close to 0 , the distribution is equitable, and if It is close to 1, it is huge inequality. In Pakistan, this value is .68, which shows a large income gap.

HIES: Household Income and Expenditure Survey

PIHS: Pakistan Integrated Household Survey

\section{Literature review}

Kuznet's curve is commonly used to explain the phenomenon of income inequality. Nobel laureate Simon Kuznets (1901-1985) hypothesized that as economy grows income inequality cycles occur naturally, driven by demand and supply forces of the market. Kuznet Curve explains that inequality arises in the beginning stages of economic growth and gradually improves with technological development. This process arises when labor moves from agricultural sector to work in industrial sector for better salaries. There might be other factors behind it, as Greenwood and Jovanovich (1990) quote that the development of financial sector widens the gap by giving access to only few. Region, social disparity, gender and education are some other causes, which play an important role in the unequal distribution of income. In early development, opportunities for investment grow for those having money, while the mobility of low-paid workers to the urban areas reduces the salaries. On the other hand, in developed countries workforce replaces physical capital and growth is slowed by inequality by lowering level of education for the poor, as they lack finance. The Kuznets curve suggests that as nations enter secondary section of growth, which is shifting from agriculture sector to industrial sector, economy moves to the urban areas. When farmers migrate for better salaries, this causes rural-urban gap. The income of the owners of the industries would rise at a higher rate, while laborers would suffer a much slower growth rate and incomes for agricultural workers will decrease. Population in the cities increases and rural population decreases.The decrease in unequal distribution of income is only hoped, when at some average income, the concept of welfare state arises and democracy prevails, which increases the income per capita. That's why the Kuznets curve has inverted "U" shape.

Kuznet's curve theory has been criticized by arguing that the U shape does not follow the progress in the development of a single country, but rather differences, which arise historically between countries. For example, Kuznet's curve data used in Latin America gave expected results because the inequality, there was historically high. When this variable is controlled, the U shape gradually disappears (Deininger\& Squire, 1998).). When considering empirical evidence from a large number of countries, Fields (2001) refutes the Kuznets hypothesis. David Lempert took historical changes into account and attached time and political considerations to the Kuznets curve, telling how these factors effect inequality, resulting either in stability or collapse.

The example of East Asian miracle defies the validity of Kuznets theory. The eight countries - Japan, South Korea, Hong Kong, Taiwan, Singapore, Indonesia, Thailand and Malaysia developed at a rapid pace with decrease in poverty level and balanced distribution of income, which was contrary to the phenomenon of Kuznets. Joseph Stiglitz explains this balanced growth by arguing that it is the result of reinvestment in land reforms, which helped in increasing rural development, providing equality in education, what Stiglitz names an "intellectual infrastructure" for economic growth and future planning for increasing wages and limiting prices of the commodities.

Gabriel Palma who works as a Lecturer in Cambridge University points out that, there is no indication of inequality for a 'Kuznets curve':

The statistical evidence for the 'upwards' side of the 'Inverted-U' between in equality and income per capita seems to have vanished, as many low and low-middle income countries now have a distribution of income similar to that of most middle-income countries (other than those of Latin America and Southern Africa). That is, half of Sub-Saharan Africa and many countries in Asian, including India, Chinaand Vietnam, now have an income distribu- 
tion similar to that found in North Africa, the Caribbean and the second-tier NICs. And this level is also similar to that of half of the the first-tier NICs, the Mediterranean EU and the Anglophone OECD (excluding theUS). As a result, about $80 \%$ of the world population now live in countries with a Giniaround 40 .

Palma further notes that, only middle-income nations of Latin America and South Africa show large income inequalities. He breaks inequalities into deciles, each of which contains $10 \%$ of the population presenting two trends in distribution in an economy. One is 'centrifugal', and takes place at the two tails of the distribution-leading to an

increased diversity across country in the shares appropriated by the top 10 percent and bottom forty percent. The other is 'centripetal', and takes place in the middle-leading to to a remarkable uniformity across countries in the share of income going to the half ofthe population located between deciles 5 to 9 .

It is clear that, $10 \%$ of the richest population affects the income of the $40 \%$ poorest population all across the world.

The method most commonly used in Pakistan to measure unequal distribution of income is by estimating Gini's coefficient, based on Lorenz's curve. The economists who used this technique for Pakistan are Haq(1964), Khandkar(1973), Suleman(1973), Kruijk(1986), Haq(1998), and Ali \&Tahir(1999).

According to Sen(1974) equality can be described by statistical measures like Gini's coefficient, Lorenz curve and coefficient of Variation or by Atkinson's indices, which give highly significant results in studies of income distribution. He evaluated many other simple measures, detailing their comparative advantages and disadvantages. Alauddin (1975) estimated Gini's coefficient for both urban and rural population. He found a constant decline in inequality during 1963-64 to 1969-70 in the rural areas, whereas in urban areas he found a different trend. It showed increase in 196667 and lowered in 1969-70. Kakwani (1980) employed the technique of Lorenz's curve to study the interaction between different variables of economic growth. He pointed out difficulty in identifying some intersections in Lorenz's curve, leading to ambiguous results. He introduced a new Lorenz curve to overcome this problem called concentration curve.

Ercelawn (1988) used data by HIES for 1971-72 and 1979 with a gap of seven years between the two surveys and analyzed the inferences ofrural inequality change. He concluded that the economic measures taken at that time were unsuccessful in bridging the gap. Ahmed and Ludlow (1989)measured inequality for 1979 and 1984-1985 with the help of coefficient of Variation, logarithmic Variance, Gini coefficient, Atkinson's indices and the Lorenz curves. They used consumption data for household and found a wider gap in rural areas with respect to urban areas. Jafri and Khattak (1995) compared changes in inequality in urban and rural areas both during 1979-1991 with the help of Gini coefficient. They concluded that during 1979-88 disparities declined in urban and rural areas both but in 1990-1991, it expanded sharply in both the regions.

Deininger and Squire (1998) tried to find a link between high growth and increasing disparity, but could not find any solid evidence to prove this relationship between the two. High growth was linked with the increasing inequality in the same manner as it was associated with the lowering inequality. Ravallion and Chen (1997) were unable to find any hierarchal link between rapid growth and unequal distribution. Piketty (1998) interrogates that unequal distribution of wealth can affect the mobility of labor among generations, and central unit can linger the constancy in unequal distribution of wages. Goudie and Ladd (1999) state that high inequality can affect negatively by lowering growth rate. Economies with high inequality in land and consumption, fail to reduce poverty level because their policies change the economic growth but with slower reduction in poverty. Generalizing the consequences of change in Inequality upon economic development is not possible.

Ahmad (2001) compared inequalities between occupations by calculating Gini coefficients of varied professions in Pakistan with the help of data for 1992-93 by HIES. He found out that the level of inequality was highest in the case of skilled workers and lowest in the case of professionals. He also evaluated that the inequality level in skilled labor was greater than the national inequality and inequality in case of professionals are too lower than the overall level of Inequality in Pakistan. Kakwani (2004) studied the interrelationship between inequality in economic development and poverty. The author explained to what extent the economic growth benefits poor, through the pro poor growth index with the name of Poverty Equivalent Growth Rate (PEGR). It examines the magnitude and opportunities of growth, which poor receive. It was recommended that the maximization of PEGR along with the growth rate could help in the rapid reduction of poverty.

Anwar (2004) analyzed the inequality trend during 1998-99 and 2001-02 by taking domestic expenditure as indicator of standard of living. He concluded that inequality expanded in Pakistan between this period. It simultaneously increased in rural regions and lowered in city regions.

Pakistan Economic Survey (2006-07) indicates that on the basis of consumption, Gini coefficient rose in Pakistan marginally during 2001 and 2005.

\subsection{The role of education}

Various economists and researchers have evaluated the relationship between education and income inequality and concluded that an inverse relationship exists between the level of schooling and inequality. Psacharopoulos. et al., Park and De Gregorio and Lee found a negative relationship between average levels of schooling attainment of a nation and inequality, which means that when average level of schooling increases, inequality falls. Barro concluded the same relationship, but he only confirmed it for primary schooling attainment. He found that inequality increases with higher education. Barro and Alderson and Nielson examined the effect of enrolments in education on inequality and found out that higher enrolment's lower inequality, especially at tertiary level of education, however Barron found an inverse relationship only between the enrolments in primary education and inequality but found that, there exists a direct relationship between higher schooling enrolments and inequality.

Azfar, Bergan, Naseem, Khandkar, Kruijkand Leauwen, Kemal, and Guisinger and Hicks are some of the researchers who conducted studies on Pakistan. Bergan and Azfar have computed Gini coefficients for both rural and urban areas. According to Bergan, when compared with other developing countries, income inequalities in Pakistan were lower. In urban areas, inequalities were higher as compared to rural areas. The Gini coefficient was 0.357 for rural areas and 0.430 for urban areas, while the overall value of Gini's coefficient for Pakistan was 0.381. The values of Gini's coefficient calculated by Azfar declined slightly than the values measured by Bergan. It declined to 0.334 for rural areas, 0.424 for urban areas and 0.365 for both the areas.

Similarly, Khandkar study confirmed that inequalities in urban areas were higher than the rural areas. Kruijk and Leauwen examined the trend in inequalities in rural and urban areas and Pakistan as a whole during 1969-70 and 1979 by calculating Gini's coefficient. They analyzed that inequality expanded during 1969-70 and 1979 in both the rural and urban areas. They also found out that inequalities were higher in urban areas as compared to the rural areas just like other studies. The Gini coefficient was 0.329 for Pakistan for the period $1969-70$ and 0.376 for 1979. It is examined that during 1980s distribution of income improved from 0.428 in $1984-85$ to 0.348 in 1987-88. It rose to 0.407 in $1990-91$ and lingered till 1998-99. The situation of inequality has worsened in Pakistan in the decade of nineties. Since 1990-91 inequality increased relatively in rural areas as compared with urban areas. However, the value of Gini's coefficient lowered to 0.275 in 2001. The table below shows the value of Gini's coefficients from 199899 till 2010-11. 
Table 1: Source: Pakistan Millennium Development Goals

\begin{tabular}{|c|c|c|c|c|c|c|c|}
\hline Year & Region & $1998 / 99$ & $2001 / 02$ & $2004 / 05$ & $2005 / 06$ & $2007 / 08$ & $2010 / 11$ \\
\hline \multirow{8}{*}{$\begin{array}{l}\text { Gini } \\
\text { Coefficient }\end{array}$} & Pakistan & 0.3027 & 0.275 & 0.2976 & 0.3018 & 0.2897 & 0.2752 \\
\hline & & & & & & & \\
\hline & Punjab & 0.3113 & 0.2746 & 0.3043 & 0.3 & 0.2891 & 0.2832 \\
\hline & Sindh & 0.3082 & 0.303 & 0.3023 & 0.3162 & 0.2997 & 0.2825 \\
\hline & $\mathrm{KP}$ & 0.2684 & 0.2273 & 0.2533 & 0.2627 & 0.2531 & 0.2379 \\
\hline & Balochistan & 0.2319 & 0.2065 & 0.2394 & 0.2451 & 0.2327 & 0.1899 \\
\hline & Rural & 0.2526 & 0.2367 & 0.2519 & 0.2462 & 0.2529 & 0.2371 \\
\hline & Urban & 0.3607 & 0.3222 & 0.3388 & 0.349 & 0.3245 & 0.3124 \\
\hline
\end{tabular}

Table 2: Source: Pakistan Millennium Development Goals

\begin{tabular}{|c|c|c|c|c|c|c|}
\hline & across & Districts & & Net & Enrolment & Rate \\
\hline \multirow[t]{2}{*}{ Prvince } & $2004 / 05$ & & $2006 / 07$ & & $2008 / 09$ & $2010 / 11$ \\
\hline & Range & (No of & Districts) & & & \\
\hline Punjab & $46(35)$ & & $46(35)$ & & $41(36)$ & $41(37)$ \\
\hline Sindh & $40(26)$ & & $34(16)$ & & $33(22)$ & $38(24)$ \\
\hline $\mathrm{KP}$ & $43(24)$ & & $45(24)$ & & $35(24)$ & $52(24)$ \\
\hline \multirow[t]{2}{*}{ Balochistan } & $44(24)$ & & $48(26)$ & & $59(28)$ & $58(30)$ \\
\hline & \multicolumn{4}{|c|}{ Coefficient of Variation } & $(\%)$ & \\
\hline Punjab & 21 & & 18 & & 18 & 16 \\
\hline Sindh & 20 & & 20 & & 17 & 17 \\
\hline \multirow[t]{2}{*}{ Balochistan } & 31 & & 29 & & 34 & 38 \\
\hline & \multicolumn{5}{|c|}{ Rank correlation (between 2004/05 and 2010/11) } & \\
\hline Punjab & \multicolumn{6}{|c|}{0.84} \\
\hline Sindh & \multicolumn{6}{|c|}{0.33} \\
\hline KP & \multicolumn{6}{|c|}{0.75} \\
\hline Balochistan & \multicolumn{6}{|c|}{0.24} \\
\hline
\end{tabular}

As seen Gini coefficient does not show extreme inequalities. It lies between 0.3027 and 0.2752 . Inequality has narrowed over the las few years.

Under Article 25a of the constitution of Pakistan, every citizen of the state has a right to attain education and it is state's responsibility to give free access to schooling to all the children from five to eighteen years of age. Progress is measured by assessing three indicators: Primary Enrolment Rate, Completion Rate (grades 1-5) and Adult Literacy Rate. The enrolment rates across the provinces reveal marked differences: Punjab is at number one with the highest rate, then Sindh and Khyber Pakhtunkhwa, Balochistan is far behind them. The table below presents the summary of disparity among the districts in net enrolment rates. The inequalities have increased by 2010/11 within Balochistan and Khyber Pakhtunkhwa, but decreased marginally in the other two provinces. Another measure of inequality is coefficient of variation $(\mathrm{CV})$. It is more accurate than the range.The higher the $\mathrm{CV}$, the higher the inequality.

In the same manner, Punjab holds the highest position, in the completion of primary education and literacy rates.

On the basis of various studies reviewed, some key features are:

1) The earnings distribution for both the male and female gender is unequal.

2) The inequality is higher in males than in female labor force. The studies suggest that very few earners of the labor force receive the greater portion of earnings.
3) There is more inequality in the urban areas as compared to the rural areas. Low earnings inequality of rural areas is due to the homogeneity of the labor force engaged mostly in agricultural and farming activities. On the other hand in urban areas labor force is heterogeneous, involved in different professions. They are differentiated on the basis of training, skills and education. Different employment opportunities are available in urban areas which results in variation in incomes.

4) Green Revolution has helped in improving the inequalities. Previous studies have relatively focused more on factors other than impact of education on inequality, when in reality most of the variation in income inequality is caused by education. This study will try to fill this gap by examining the hindrances in providing equality in education in Pakistan with the help of secondary data from Pakistan social and living standard measurement (PSLM) survey, Household Income and Expenditure Survey (HIES) and Pakistan Millennium Development Goals (MDG's) of 2004-05, 2007-08 and 2010-11 for male and female, rural and urban areas of Pakistan.

\section{Research methodology}

\subsection{Research design}

This study employs quantitative, pooled cross sectional data, and assesses three indicators of progress in education: Primary Enrol- 
ment Rate, Completion Rate (grades1-5) and Adult Literacy Rate and their impact on Income Inequality. Deductive approach is applied in this research for drawing out logical inference by assessing the operational hypothesis in order to investigate the accurate result of the research question. The objective of this research is to identify the association between Income Inequality and education in Pakistan and how it is both negatively and positively related to it,at primary and higher level.

\subsection{The research process}

The research procedure is as follows:

1) The research problem: Definingand interpreting the effects of the components of education; Primary Enrolment Rate, Completion Rate (grades1-5) and Adult Literacy Rate, on Income Inequality, in this way help social welfare institutes or NGO's in deciding to establish primary school set-ups or universities.

2) Conceptualizing a research design: The philosophies of positivism and post positivism are employed, with the choice of mono method by applying deductive approach to the case study of Pakistan, using panel secondary data.

3) Instrument for data collection: The secondary data is being collected from Pakistan Social and Living Standards Measurement (PSLM) and Household Integrated Economic Survey (HIES). The surveys provide data about monthly income, employment and level of schooling of households. The data collected from these resources are reliable.

4) Selecting a sample:In HIES, the participants in the survey are individuals of age 10 years and older, both male and female, they are asked about their employment and income from main occupation, second occupation, other work, income in kind and pensions. In this study a sample of 12 is chosen from PLSM and HIES Surveys for the periods of 2004-05, 2007-2008 and 2010-11. The reason to select these periods is, to evaluate the consistency in the trend of income inequality and its dependence on education.

5) Composing a research proposal: The plan of this research is already scheduled in the proposal.

6) Tabulating data: The secondary data of main sources of in come, consumption patterns and components of educationis extracted from government authenticated websites.

7) Evaluating data: The data is recorded and inspected according to the requirement of research objective. For measuring statistical tests like regression, Pearson Correlation, ANOVA and reliability tests, statistical soft wares Stata and Spss are selected.Data is fed in Spss by appropriate coding to compute major tests.

8) Preparing research analysis report:The results of all the tests are evaluated in the form of a report after appraising the data. These results help in judging the operational hypothesis.

9) Variables

This study applies Gini Coefficient technique to calculate Income Inequality by using total income and its recipients, based on cumulative distribution function. Income disparities can be calculated in a more accurate manner by using Gini Coefficient. It can take values between 0 to1. If the value is close to 0 , the distribution is equitable and if It is close to 1 , it is huge inequality.The formula for measuring Gini Coefficient is:

$\mathrm{G}=1+1 / \mathrm{n}+2 / \mathrm{nY}-[\mathrm{y} 1+2 \mathrm{y} 2+3 \mathrm{y} 3+\ldots \ldots . .+\mathrm{nyn}]$

Where

$\mathrm{y}=$ individual income

$\mathrm{n}=$ number of earners

$\mathrm{Y}-=$ mean of individual incomes

The research is about the components of education factor, effecting the Income Inequality and computation of the intensity of these components. Primary Enrolment Rate, Completion Rate (grades1-5) and Adult Literacy Rate are independent variables, denoted by " $\mathrm{x}_{1}, \mathrm{x}_{2}$ and $\mathrm{x}_{3}$ " respectively and Income Inequality is dependent variable denoted by " $y$ " measured by using Gini Coefficients. A multiple linear regression (MLR) model of multivariable is formulated in this research. The following is the equation of the multiple linear regression.

$y=\beta o+\beta_{1} x_{1}+\beta_{2} x_{2}+\beta_{3} x_{3}+u$

Where,

$\mathrm{y}=$ is the explained variable i.e. Income Inequality (Gini Coefficient)

$\beta o=$ is a constant, which we calculate by regression

$\mathrm{x}_{1}=$ is the $1^{\text {st }}$ explanatory variable i.e. Primary Enrolment Rate

$\mathrm{x}_{2}=$ is the $2^{\text {nd }}$ explanatory variable i.e. Completion Rate (grades $1-$ 5)

$\mathrm{x}_{3}=$ is the $3^{\text {rd }}$ explanatory variable i.e. Adult Literacy Rate

$\mathrm{u}=$ is the error term or disturbance in the relationship, represents factors other than explanatory variables that affect $y$.

In this case multiple regression equation becomes as follows:

$y=\beta o+\beta_{1}$ Primary Enrolment Rate $+\beta_{2}$ Completion Rate (grades $1-5)$

\section{$+\beta_{3}$ Adult Literacy Rate $+\mathrm{u}$}

With the help of above multiple regression model, we can find out the values of $\beta$ o and all other betas. Similarly correlation can also be calculated of all variables with respect to other variables. The error term uis assumed to be zero as per Gauss Markov assumptions.

\subsection{Hypothesis}

According to information inferred while conducting literature review, Primary Enrolment Rate is inversely proportional to Income Inequality; on the other hand, some researchers have found a direct relationship between Income Inequality and tertiary education. By examining the regression and other statistical measurements for the periods 2004-05, 2007-08 and 2010-11, these hypotheses are tested.

$\mathrm{Ho}=$ There is no relationship between Primary Enrolment Rate and Income Inequality.

$\mathrm{H} 1=$ There is an inverse relationship between Primary Enrolment Rate and Income Inequality.

$\mathrm{H} 3=$ There is a direct relationship between Tertiary Education and Income Inequality

These results can help organizations that are genuinely interested to play their role for the establishment of our country as a welfare estate, by opening new educational institutes, as education plays a crucial role in determining the economic development of a state. After extracting data from the sources and mathematically calculating desired values as suggested by research objectives, coding of data in Stata and SPSS will be done for analysis of data. To check if the data is free from various biases, certain tests are available; unit root test, ADF (Augmented Dicky Fuller test), variance/covariance, White test and Granger causality test.

\section{Research analysis and findings}

\subsection{Pooled cross sectional data}

Generally researches with financial topic use quantitative data after performing much complicated statistical and mathematical calculations, but as the topic is vast and there was time constraint, this research uses processed data available at the websites of PSLM (Pakistan Social and Living Standards Measurement Sur- 
vey), HIES (Household Income and Expenditure Survey) and MDG's (Pakistan Millennium Development Goals). The pooled cross sectional data is for the periods 2004/05, 2007/08 and 2010/11 for four provinces, Punjab, Sindh, Khyber Pukhtunkhwa and Balochistan, as data for other areas like Azad Jammu and Kashmir, GB and FATA was missing for 2004/05 and 2007/08. The total number of observations is twelve, which might not be considered as a standard in generating desired results, but as these values are extracted from government authenticated websites, results of regression are as predicted by the literature review.

Gini Coefficient values are consumption based calculated using Lorenz Curve, giving complete picture of the income distribution as a whole,in terms of mean. The data is farther away from the 45 degree line, there's a higher level of income inequality. Income disparities can be calculated in a more accurate manner by using Gini Coefficient. It can take values between 0 to 1. Primary Enrolment Rate, Completion Rate (grades 1-5) and Adult Literacy Rate are in percentages. In this research, we considered Adult Literacy Rate as Tertiary Rate as it includes population of ages 15 years and older.

\subsection{Software for data analysis}

First, the data is put in Microsoft excel to obtain graphs for all the variables individually and as a complete picture of the data, then it can be transferred to SPSS and Stata soft wares either by copying it or through import and export option. Tests of regression, reliability, ANOVA test and Pearson Correlation are done by using Stata and SPSS. Other tests are unit root test, ADF (Augmented Dicky Fuller test), variance/covariance, White test and Granger's causality test.

\subsection{Multiple regression analysis}

Regression for pooled cross sectional data gives the following results for the model.

Model

$\mathrm{Y}=.14983-.0024706$ primrate +.0030528 comrate +.0022087 adurate

Table-3

The regression analysis provides us with the following results. The value of constant is high, in view of the scale of our dependent variable Gini Coefficient, which can take values between 0 and 1 . The value of $R$ square is .6706 and adjusted $R$ square is .5470 , which shows that our independent variables are significant in explaining the variation in dependent variable by $67 \%$. Adjusted $\mathrm{R}$ square is also telling us that our variables are significant as it takes penalty of insignificant variables and can reduce to negative value.

\subsection{Pearson correlation analysis}

The Pearson Correlation reveals moderate correlation of Gini Coefficient with Primary Enrolment Rate. Whereas, it shows a weak correlation between Gini Coefficient and Completion Rate (grades 1-5) and Adult Literacy Rate.

The ANOVA test is showing the F-statistic as 5.428, which is a significant value telling us that our regression line is a good fit.

\section{Interpretation and conclusion}

\subsection{Conclusion}

The regression model results are

$\mathrm{Y}=.14983-.0024706$ primrate +.0030528 comrate +.0022087 adurate
It can be inferred that the Gini Coefficient is negatively related to Primary Enrolment Rate, where as it is positively related to Completion Rate (grades 1-5) and Adult Literacy Rate. The values of beta coefficients are helpful in telling us that if the Primary Enrolment rate increases by $10 \%$ then the Gini Coefficient decreases by .025 which indicates the low effect of Primary Enrolment Rate on Income Inequality. The possible reasons are a small amount of observations and a large number of factors, which are responsible for disparities in income in any country. From the betas of Completion Rate (ages 1-5) and Adult Literacy Rate, it can be inferred that a $10 \%$ change in Completion Rate (ages 1-5) increases the Gini Coefficient by .031 and $10 \%$ increase in Adult Literacy Rate increases the Gini by .02 .

By putting the value of 1 for all independent variables we get the following results:

$Y=.14983-.0024706+.0030528+.0022087$

$Y=.1526209$

We can conclude from the above computation that if all the explanatory variables decrease or increase by one percent then overall effect on Gini is .15 . We reject the null hypothesis by saying that education effects Income Inequality.The results are in consistence with Barro's study, who concluded that primary education helps in reducing Income Inequality, whereas higher qualifications increase inequality.

\subsection{Recommendations}

This research was conducted to verify the relationship between education and Income Inequality, Which is proved through empirical observations by employing the philosophy of positivism, as verifiability is the essence of positivism. As per Literature Review, most of the researches have proved a negative relationship between education and Income Inequality even though some researches have given contradictory results. According to Popper, a research must be considered as scientific and is distinguished from pseudoscience, if it is able to be falsified. This research has not only proved a relationship between education and Income Inequality but it has falsified the concept that the relationship is purely negative, because the education at primary level is unambiguously negatively associated to Income Inequality but it shows a positive relationship at tertiary level.

The main reason for this contradiction in Pakistan is the huge gap between salaries of people with primary education and high qualified professionals. The authorities should take measures to set minimum salaries for people with low levels of education, which can help in mitigating the disparities in salaries and make our country, a welfare state. Social welfare associations or NGO's can play their role by opening more primary schools than universities and promoting awareness programs in villages toeradicate gender discrimination.

\subsection{Suggested areas for further research}

This research tries to test the hypothesis of the impact of education on Income Inequality. Income Inequality is caused by a large number of factors. This is a broad topic and future researches can be performed by using numerous statistical measures to compute Income Inequality like Gini coefficient, Lorenz curve and coefficient of Variation or by Atkinson indices which give highly significant results in studies of income distribution. Studies can also be done by taking education as number of years. There is a vast area for future researches by taking other factors into account and calculating their intensity in causing variations in Income Inequality.

\section{References}

[1] Ali, L., Ramay, M. I., \&Nas, Z. (2013). Analysis of the determinants of income and income gap between urban and rural Pakistan. 
Interdisciplinary Journal of Contemporary Research in Business, 5 (1), Retrieved from http://journal-archieves32.webs.com/858 885.pdf.

[2] Asad, A., Ahmed, M. (2011). Growth and consumption inequality in Pakistan.Pakistan Economic and Social Review, 49(1), 69-89. Retrieved from http://pu.edu.pk/images/journal/pesr/PDFFILES/4\%20ASAD\%20Growth\%20and\%20Consumption \%20Ineq uality.pdf.

[3] Farooq, M. (2010). Education and income inequality in Pakistan.The Dialogue, $V$ (3), 228-240. Retrieved from http://www.qurtuba.edu.pk/thedialogue/The\%20Dialogue/5_3/Di alogue_July_September2010_228-240.pdf.

[4] Haq, R. (1999). Income inequality and economic welfare: A decomposition analysis for the household sector in Pakistan. Pakistan Institute of Development Economics, (170). Retrievedfromhttp://www.pide.org.pk/pdf/rr/RR170.pdf.

[5] Jamal, H., \& Khan, A. J. (2005). The knowledge divide: Education inequality in Pakistan. The Lahore Journal of Economics, 10 (1), 83 - 104. Retrieved from ttp://121.52.153.179/JOURNAL/vol10NoI/Haroon\%20Jamal.pdf.

[6] Kakar, Z.K., Khilji, B.A., Khan, M.J. (2011). Relationship between education and economic Growth in Pakistan: A time series analysis. Journal of International Academic Research, 11(1). Retrieved from http://www.uedpress.org/ojs/index.php/jiar/article/view/19/49

[7] Khanam, F. Primary education expansion, income inequality and poverty reduction (Doctoral dissertation). Retrieved from http://saicon2011.ciitlahore.edu.pk/Economics/1193.pdf.

[8] Ministry of Planning. (2013). Pakistan millennium development goals. Retrieved from http://www.undp.org/content/dam/pakistan/docs/MDGs/MDG2013 Report/UNDP- Report13.pdf. 